\title{
RELAÇÃO DE TRANSMISSIBILIDADE DA MICROBIOTA BUCAL ENTRE PARES MÃES-FILHOS
}

\author{
Ana Carolina Soares Fraga Zaze ${ }^{1}$ \\ Cinthia Alves Tondatti ${ }^{2}$ \\ Renata Gamberini ${ }^{2}$ \\ Veruska de João Malheiros Pfau ${ }^{3}$
}

ZAZE, A. C. S. F.; TONDATTI, C. A.; GAMBERINI, R.; PFAU, V. de J. M. Relação de transmissibilidade da microbiota bucal entre pares mães-filhos. Arq. Cienc. Saúde UNIPAR, Umuarama, v. 18, n. 3, p, 145-150, set./dez. 2014.

\begin{abstract}
RESUMO: As principais doenças que acometem a cavidade bucal, como a cárie e as doenças periodontais apresentam sua etiologia relacionada à presença de micro-organismos específicos. Esta pesquisa tem como objetivo conhecer a relação de transmissibilidade de micro-organismos presentes na microbiota bucal entre mães e filhos, verificar sua relação e avaliar a presença de doenças bucais nas mães e sua possível interferência na transmissibilidade, identificando os grupos bacterianos mais prevalentes na cavidade bucal de crianças entre 1 a 5 anos de idade e suas mães. Foram selecionados para a pesquisa 10 pares mãe-filho que frequentam a clínica Bebê-Dente da UNIPAR Umuarama onde foi realizada a coleta do biofilme supragengival e subgengival com cones de papel absorvente estéreis para posterior análise microbiológica. A partir da coleta e análises realizadas, foi verificado crescimento microbiano nas placas de Petri, e microscopicamente detectou-se a presença de cocos, estreptococos, estafilococos e bacilos, o grau de semelhança em relação à coloração de Gram e a atividade da doença cárie. Alguns autores consideram a mãe como a principal fonte de transmissão da microbiota bucal, afirmando que a transmissão provavelmente acontece pelo íntimo contato da mãe com o filho. Concluiu-se com esta pesquisa que o padrão de transmissibilidade dos micro-organismos bucais é determinado pelas mães, ou seja, ocorre uma transmissão vertical. Por isso, é de suma importância conscientizá-las, por meio de programas preventivos, para evitar que aconteça a transmissão de micro-organismos, e consequentemente, a redução do risco de contaminação e desenvolvimento da cárie nas crianças.
\end{abstract}

PALAVRAS-CHAVE: Transmissibilidade; Micro-organismos; Mãe-filho; Cárie.

\section{ORAL MICROBIOTA TRANSMISSIBILITY RELATIONSHIP BETWEEN MOTHER-CHILD PAIRS}

\begin{abstract}
The main diseases affecting the oral cavity, such as caries and periodontal diseases, have their etiology related to the presence of specific microorganisms. This study has the objective of analyzing the microorganism transmissibility relationship found in oral flora between mothers and their children and evaluate the presence of oral diseases in mothers and the possible interference in transmissibility, identifying the bacterial groups that are the most prevalent in the oral cavities of children aged between 1 and 5 years and their mothers. Ten pairs of mothers and children that are usually seen at "Bebê - Dente" clinic, at UNIPAR (Umuarama), were selected for this research. In the clinic, tooth biofilm was collected using sterilized absorbent paper cones. From the samples collected and analyzed, it could be observed that all the samples presented microbial growth, and the presence of cocci, streptococci, staphylococci and bacilli, the degree of similarity in relation to Gram stain and cavity activity were microscopically detected. Some authors consider the mother as the major source of transmission of the oral microflora. They state that this transmission probably occurs due to the intimate contact between mother and child. With this study, it was concluded that the oral microorganism transmissibility standard is determined by the mother. Thus, it is of utmost importance to make mothers aware of this fact by preventive programs, in order to avoid that the transmission happens. Consequently, the risk of contamination and development of caries on the child will be reduced.
\end{abstract}

KEYWORDS: Transmissibility; Microorganisms; Mother-child; Caries.

\section{Introdução}

A cárie é considerada uma doença multifatorial. Esta terminologia é utilizada para explicar o desenvolvimento da doença que está relacionado principalmente a três fatores etiológicos primários, sendo eles a presença do Streptococcus mutans, principal patógeno do desenvolvimento da doença cárie, da sacarose como um adequado substrato e o dente como hospedeiro, considerando que o tempo em que se desenvolve essa tríade é determinante para o desenvolvimento da cárie dentária, de acordo com Newbrum (1988).

O processo de formação da placa dental envolve fenômenos de aderência e crescimento bacteriano ao hospedeiro na cavidade bucal, isto ocorre nos primeiros dias de vida do neonato em que este começa a ter sua microbiota bucal estabelecida (ROCHA; NASCIMENTO; PEREIRA, 2004).

A falta de acesso odontológico para crianças de 0 a 5 anos e a falta de informação dos responsáveis quanto à importância dos cuidados na dentição decídua ficou bastante clara no estudo de Dias (1995), em que 42,59\% das crianças apresentavam necessidade de tratamento, incluindo superfícies com extrações indicadas e restaurações. Para o mesmo autor, estudos de manchas brancas, utilizando o índice de ceo-s, 4,32\% das superfícies examinadas apresentavam este tipo de lesão. Crianças com ceo-s igual a 0 (zero) e livres de mancha branca representaram um total de apenas 33,44\% dos pacientes examinados. O que denota que o número de crianças que apresentam atividade de cárie nesta faixa etária é alto.

De acordo com Bönecker; Guedes-Pinto; Walter (1997) os valores dos índices de ceo-d e ceo-s expressam quase que exclusivamente o número médio de lesões de cárie encontradas. Na faixa etária entre 1 e 2 anos, encontra-se em média 2,5 dentes acometidos por cárie, enquanto na faixa de

DOI: https://doi.org/10.25110/arqsaude.v18i3.2014.5189

${ }^{1}$ Professora Doutora do Curso de Odontologia da Universidade Paranaense - UNIPAR- Umuarama/PR.

${ }^{2}$ Cirurgiã-Dentista, Graduada pelo Curso de Odontologia da Universidade Paranaense - UNIPAR - Umuarama/PR.

${ }^{3}$ Professora Mestre do Curso de Odontologia da Universidade Paranaense - UNIPAR - Umuarama/PR.

Praça Mascarenhas de Moraes, s/n. Clínica Odontológica - Umuarama-PR - CEP: 87502-210, Telefone: (044) 3621-2844, Email: carolzaze@unipar.br 
2 e 3 anos, a media é de 3,9. O que demonstra um elevado aumento do índice de cárie em curto espaço de tempo.

Na década de 60, os estudos atribuídos por Fitzgerald e Keyes (1960) deram um passo maior para a crença de que haviam bactérias específicas responsáveis pela doença cárie. Vários estudos vêm tentando identificar a sua origem e sua transmissão entre humanos.

Alguns micro-organismos específicos são relacionados à cárie, sendo o principal deles o Streptococcus mutans, que constitui uma microbiota altamente cariogênica e pode ser encontrado no biofilme bucal de seres humanos, rotineiramente. A colonização destas bactérias ocorre precocemente à erupção dos primeiros dentes do bebê e sua instalação ocorre com maior predileção em dentes com áreas retentivas, onde é mais difícil à higienização. Ocorre também no dorso da língua (DUTRA; AZEVEDO; FIGUEIREDO, 1997).

Sabe-se que a colonização da cavidade bucal inicia-se nos primeiros momentos após o nascimento e continua por toda a vida do indivíduo. Crianças com o meio bucal em desenvolvimento são mais susceptíveis à colonização bacteriana, porém apenas após o irrompimento dos dentes ocorre um aumento de sítios disponíveis para a aderência e estabelecimento do Streptococcus mutans, dado confirmado no estudo realizado por Carlsson, Olsson e Bratthall (1989), no qual os autores afirmaram que não encontraram colônias destes micro-organismos nas crianças avaliadas entre as três horas e o quinto dia após o nascimento.

A dominância dos Streptococcus mutans determina o início do processo cariogênico. Logo, para prevenir a cárie, faz-se necessário retardar a transmissão desses micro-organismos e evitar a sua proliferação, reduzindo assim a possibilidade de contagens microbianas acima daquelas consideradas naturais na saliva (RAMOS; MAIA, 1999)

A aquisição inicial do Streptococcus mutans também foi observada por Caulfield et al., (1993), o qual encontrou o microrganismo em 36 crianças, na idade média de 26 meses, sendo este período descrito como Janela da infectividade.

Não só a presença, mas também a idade em que ocorre a colonização pelo grupo mutans, são importantes para o desenvolvimento da lesão cariosa. Fujiwara et al., (1991) concluíram que uma infecção precoce pelos estreptococos cariogênicos aumenta, significativamente, o risco de cárie na dentição decídua. Verificaram também que, os níveis salivares maternos do grupo mutans estavam relacionados com o desenvolvimento da cárie nos seus filhos, isto é, crianças cujas mães tinham altos níveis salivares desses estreptococos.

A transmissibilidade é outro fator relevante quando se trata do controle da colonização bacteriana, pois sua transmissão ocorre, na maioria das vezes, no contato íntimo que há entre mãe/filho (transmissão vertical). Esse contato pode ser de forma direta (beijo na boca, saliva, soprar a comida) ou indireta (copos, talheres, escovas, utensílios, brinquedos) (CORRÊA, 1998).

Segundo Guedes-Pinto (1997), as bactérias colonizam a cavidade bucal dos bebês por meio do contato com os indivíduos do ambiente familiar, sendo que há relatos de que quanto mais precoce ocorrer a colonização bacteriana, maior será o risco do bebê desenvolver cárie.

Com relação à doença periodontal, Hugoson et al.
(2005), ao avaliarem a saúde gengival em crianças suecas, afirmaram que $31 \%$ das crianças aos 3 anos e $20 \%$ das crianças aos 5 anos eram saudáveis, mostrando que a doença aumenta com a idade. Jahn e Jahn (1997) realizaram um estudo em crianças de 1 a 5 anos de idade e verificaram o mesmo padrão de ocorrência. Em um levantamento epidemiológico denominado "Projeto SB Brasil 2003", realizado pelo Ministério da Saúde, verificou-se que 53,8\% dos indivíduos na faixa etária de 15 a 19 anos apresentam alguma alteração periodontal (BRASIL, 2004). A doença periodontal restrita aos tecidos gengivais ou com perda de inserção pode ser encontrada em crianças e adolescentes, e o diagnóstico precoce é um passo importante para prevenir a perda de elementos dentários por motivos periodontais (PIAZZINI, 1994). Sabe-se que os microrganismos, frequentemente, relacionados à doença periodontal na dentição decídua são o Aggregactibacter actinomycetemcomitans (A.a.), Capnocytophagas sputigena e Prevotella intermedia, contudo, a literatura científica a esse respeito é escassa, bem como sobre a prevalência em indivíduos menores de 6 anos.

Baseado nas informações acima, o objetivo do presente estudo foi conhecer a relação de transmissibilidade de micro-organismos presentes na microbiota bucal entre mães e filhos, identificando os grupos bacterianos mais prevalentes na cavidade bucal de crianças entre 1 a 5 anos de idade e suas mães, bem como verificar a relação da microbiota bucal entre os pares, avaliando a presença de doenças bucais nas mães e sua possível interferência na transmissibilidade.

\section{Material e Método}

Após a aprovação do presente projeto pelo Comitê de Ética em Pesquisa Envolvendo Seres Humanos (CEPEH) da Universidade Paranaense (protocolo 20196/2011), foram selecionados pares de mãe-filho, que se apresentaram para atendimento odontológico na clínica Bebê-Dente da Universidade Paranaense (UNIPAR) campus de Umuarama, no primeiro semestre do ano de 2011. Após o esclarecimento sobre a pesquisa a ser realizada e os procedimentos que seriam executados, as mães que concordaram em fazer parte da pesquisa assinaram o Termo de Consentimento Livre e Esclarecido.

Foram excluídas da amostra mães que apresentaram doenças sistêmicas que poderiam interferir na microbiota bucal, gestantes, ou que estavam realizando reposição hormonal. Também foram excluídas as mães que nos últimos seis meses foram submetidas a algum tipo de tratamento periodontal ou antibioticoterapia. Nos filhos, foram analisados parâmetros que podem ocasionar possíveis interferências sistêmicas na microbiota bucal, como diabetes mellitus e o tratamento com antibióticos nos últimos seis meses.

Foram selecionadas 10 crianças para o estudo que apresentavam idade entre 1 e 5 anos. Definida a amostra, foram preenchidas as fichas clínicas de anamnese contendo os dados pessoais tanto das mães como dos filhos. Em seguida, o cirurgião-dentista considerado como examinador do presente estudo realizou o exame clínico bucal, avaliando a presença de cárie e aspecto gengival. Para a coleta do biofilme supra e subgengival onde foi realizada a análise microbiológica, foram eleitos os dentes 72 e 54, para os filhos, e, 32 e 17 para as mães. Tais dentes foram selecionados devido ao fato de estarem localizados em diferentes regiões, anterior 
e posterior.

Em cada par mãe-filho, primeiramente foi realizada a coleta do biofilme supragengival, seguida da coleta do material subgengival. Os procedimentos foram realizados inicialmente na mãe e em seguida nos filhos.

Os dentes de onde foram extraídas as amostras bacterianas foram isolados com rolos de algodão estéreis. O biofilme supragengival foi coletado com cones de papel absorvente estéreis, e o restante do material que estava depositado na superfície do dente foi então removido com gaze estéril. Novos cones de papel absorvente estéreis foram introduzidos no sulco gengival, onde permaneceram por um período de 10 segundos.

Imediatamente após ter sido removido do sítio em questão, o cone de papel foi armazenado em um tubo de ensaio contendo o meio de cultivo caldo BHI (Brain Heart Infusion), com auxílio de uma pinça clínica estéril. O meio de cultura escolhido favorece o crescimento de microrganismos aeróbios e anaeróbios facultativos Gram-positivos e/ ou Gram-negativos. Posteriormente, as amostras microbiológicas foram levadas ao Laboratório de Microbiologia da UNIPAR, e processadas para a identificação das culturas. Os tubos que continham as amostras foram incubados em estufa de cultura a 37 graus Celsius $\left({ }^{\circ} \mathrm{C}\right)$ durante 48 horas.

Após o período de incubação, os tubos que apresentaram crescimento microbiano, visualizado por meio de turbidez do meio de cultura, foram transferidos para meios de cultura sólidos (em placa de Petri) para obtenção de colônias isoladas e posterior identificação microscópica. Para auxiliar as transferências para as placas, foi utilizada uma alça de platina, feito semeadura pela técnica do esgotamento. Os meios selecionados foram o Agar Mac-Conkey e o Agar sangue. O primeiro meio foi utilizado para seleção das bactérias Gram-negativas, enquanto o segundo meio, por ser altamente nutritivo, permitia crescimento tanto de bactérias Gram-positivas quanto Gram-negativas.

Em seguida, as placas foram incubadas em estufa de cultura a 37 graus Celsius $\left({ }^{\circ} \mathrm{C}^{\circ}\right)$ durante 48 horas. Foram avaliadas em relação aos aspectos de crescimento, sendo selecionadas colônias isoladas para realização de avaliação microscópica para confirmação do tipo de Gram, e ainda a identificação baseada nos formatos e arranjos bacterianos, o que foi possível mediante a preparação de lâminas e realização da coloração de Gram.

Os dados referentes a coloração de Gram (diferenciados como Gram-positivos e Gram-negativos, além da sua relação aos formatos e arranjos bacterianos) foram utilizados de forma qualitativa e comparativa, os quais possibilitaram a descrição de parâmetros de semelhança para a análise deste tipo de microscopia. Sendo assim, foram considerados os seguintes critérios: Total semelhança (quando mãe e filho apresentaram características semelhantes para todas as amostras testadas); Alguma semelhança (quando mãe e filho apresentaram uma ou mais amostras semelhantes quanto ao aspecto microscópico e tipo de Gram); Nenhuma semelhança (mãe e filho com características microscópicas totalmente diferentes).

Os resultados foram tabulados de forma descritiva, fornecendo tabelas e gráficos de frequência absoluta e percentual. Os dados obtidos neste estudo foram divulgados por meio de palestras educativas, ministradas no projeto de extensão universitária "Clínica Bebê-Dente". Futuramente serão elaborados folhetos explicativos que serão disponibilizados nas salas de espera das clínicas odontológicas.

\section{Resultados}

A análise microbiológica demonstrou $100 \%$ de crescimento microbiano em meio BHI e em meio de cultura Ágar sangue. Porém, em meio Agar MacConkey, observou-se crescimento em apenas 30\% das amostras das mães e em $20 \%$ dos filhos.

Observou-se a presença de hemólise parcial em meio de cultura Agar Sangue tanto nas mães quanto nos filhos. Cerca de $80 \%$ das mães e $100 \%$ dos filhos apresentaram esta característica na região supragengival. As amostras subgengivais apresentaram hemólise em $70 \%$ das amostras, tanto para mães quanto para filhos.

Em relação à análise microscópica realizada com as colônias crescidas nas placas foi possível constatar que todas as amostras, em ambos os meios, demonstraram aspectos morfológicos de cocos e estreptococos (100\%), tanto nas mães quanto nos filhos, e em menor número foi detectado a presença de estafilococos (50\%), tanto para as mães quanto para os filhos, e bacilos para as mães $(20 \%)$ e para os filhos $(10 \%)$, de acordo com a figura 1 .

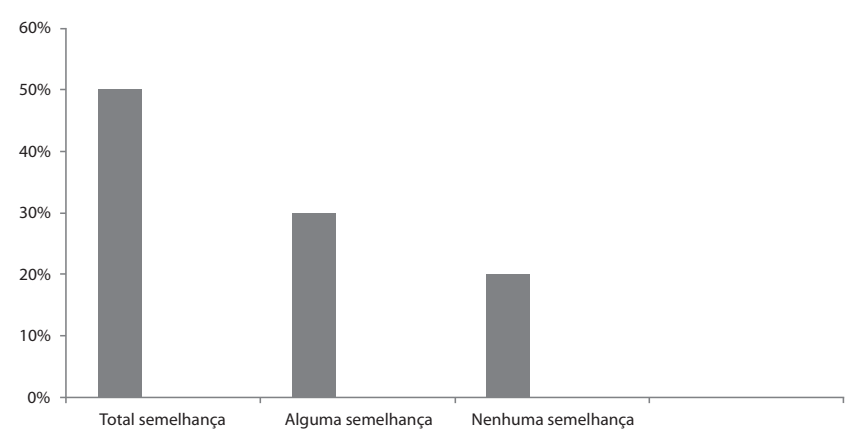

Figura 1: Aspectos morfológicos bacterianos em amostras semeadas em Agar Sangue e Agar MacConkey, nos pares mães-filhos. Análise realizada após incubação de $37^{\circ} \mathrm{C}$ por $48 \mathrm{~h}$.

Em relação à similaridade pela coloração de Gram, foi verificado que $50 \%$ dos pares mães-filhos apresentaram total semelhança no aspecto microscópico supragengival, enquanto $30 \%$ dos pares apresentaram alguma semelhança e $20 \%$ não apresentaram nenhuma semelhança, conforme pode ser observado no figura 2.

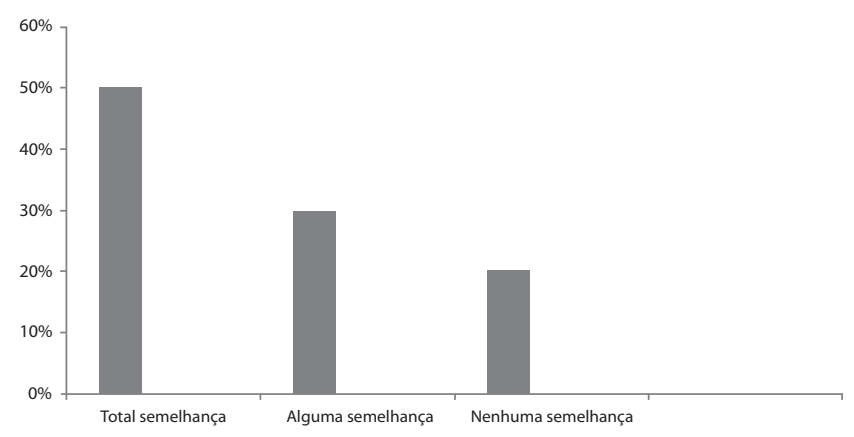

Figura 2: Relação da característica microscópica supragengival entre os pares mães-filhos.

Para as amostras coletadas na região subgengival 
foi verificado que $30 \%$ dos pares apresentaram total semelhança no aspecto microscópico, enquanto 30\% apresentaram alguma semelhança e $40 \%$ dos pares não apresentaram nenhuma semelhança no aspecto microscópico subgengival, conforme figura 3 .

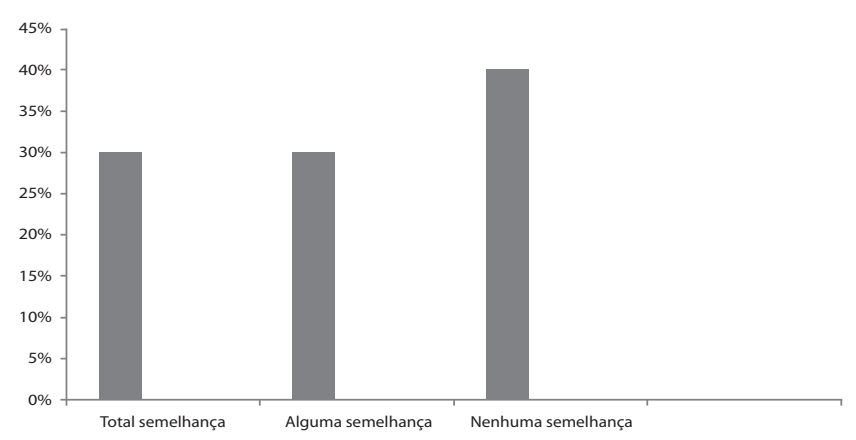

Figura 3: Relação da característica microscópica subgengival entre os pares, mães-filhos.

De forma geral, considerando as amostras tanto supragengival quanto subgengival, nos pares mães-filhos, as características de relação da microbiota verificada, $70 \%$ das análises apresentaram total semelhança, 20\% alguma semelhança e $10 \%$ nenhuma semelhança.

No exame clínico bucal, foi verificado que 50\% das mães apresentaram a doença cárie, sendo que seus filhos também já apresentavam sinais de atividade desta doença. Foi observado que as mães que apresentavam condições de saúde bucal, determinada pela ausência dos sinais clínicos referentes à doença cárie, tinham filhos com as mesmas características. Com relação à presença de sinais característicos das doenças periodontais, nenhum dos indivíduos pertencentes à amostra os apresentava.

\section{Discussão}

A cárie dentária é considerada uma doença multifatorial que segundo Keyes (1962), para sua instalação necessita da interação de três fatores básicos: a microbiota, o hospedeiro e a dieta. A interação desses fatores gera a doença que se manifesta por meio de um sintoma clínico, a lesão cariosa ou simplesmente cárie (WALTER, 1987). Para Newbrun (1988), o tempo também é mais um dos fatores importantes para a progressão da lesão.

A Doença Periodontal é a segunda de maior importância epidemiológica para a Odontologia, contudo foi negligenciada pelos profissionais da área durante anos, principalmente quando se trata de pacientes infantis. Sua etiologia está relacionada a fatores locais e sistêmicos, e dentre eles, a presença de micro-organismos específicos é considerada um fator determinante (GUEDES-PINTO, 1997).

O período de aquisição do Streptococus mutans é de extrema importância visto que quanto mais precoce for sua presença na cavidade bucal dos bebês, maior será o risco de desenvolvimento da cárie. (FUJIWARA et al., 1991; FERNANDES; GUEDES-PINTO, 1997; TORRIANI; BUSATO, 2002) Assim, prevenindo a infecção precoce por Streptococus mutans, o dente terá condições de resistir à infecção por estes micro-organismos (TORRIANI; BUSATO, 2002)

Os níveis salivares maternos do grupo mutans estão relacionados com o desenvolvimento da cárie nos seus filhos, isto é, crianças cujas mães apresentam altos níveis salivares desses estreptococos estão mais suscetíveis à doença cárie (FUJIWARA et al., 1991). Outros autores consideram a mãe como a principal fonte de transmissão da microbiota oral (SOCRANSKY; MANGANIELLO, 1971; BERKOWITZ; JORDAN; WHITE, 1975), tanto dos micro-organismos relacionados à cárie como da doença periodontal (ROSELL; MONTANDON-POMPEU; VALSECKJ, 1999).

A transmissibilidade é um fator relevante quando se trata do controle da colonização bacteriana, pois segundo Corrêa (1998), a transmissão ocorre na maioria das vezes por meio do contato íntimo que há entre mãe/filho (transmissão vertical).

No presente estudo, um dos pares mãe-filho, apresentou características de total semelhança no aspecto microbiológico, já outro par não apresentou semelhança tanto supragengival quanto subgengival. Contudo, considerando as características apresentadas no exame clínico, observou-se um padrão. Nas mães com atividade de cárie, as crianças também apresentavam a doença, o mesmo foi observado na ausência da doença, mães saudáveis tinham filhos sem cárie.

Quando avaliamos os aspectos microscópicos de nossas análises, observamos que $50 \%$ dos pares mãe/filho apresentam total semelhança nos resultados das amostras supragengivais. Nas amostras subgengivais, esta proporção é reduzida para apenas $30 \%$.

Considerando que a hemólise parcial auxilia como indicativo para uma possível confirmação para os estreptococos do grupo mutans e que $80 \%$ das mães pertencentes à amostra estudada apresentaram resultados positivos para este teste, pode-se considerar que a maioria das crianças está sujeita à contaminação por esta bactéria, portanto, 100\% dos filhos apresentam microbiota cariogênica, sendo que nem todos apresentam a doença.

Com relação à doença periodontal, Hugoson et al., (2005), avaliando a saúde gengival em crianças suecas afirmaram que a doença aumenta com a idade. Jahn e Jahn (1997) realizaram um estudo em crianças de 1 a 5 anos de idade e também verificaram o mesmo.

Crianças de até 3 anos de idade não apresentam o Aggregatibacter actinomycetemcomitans (A.a)., e Porpphyromonas gingivalis em sua microbiota oral, o que sugere uma suscetibilidade adquirida a estas bactérias na vida adulta (IRFAN et al., 1999). Também existem relatos de que a colonização pelo A.a. é estabelecida dos 5 aos 7 anos (ALALUUSA; ASIKAINEN; LAL, 1991; PINTO, 1998). Segundo Zambon (1999), para manifestar a periodontite, o paciente precisa ficar infectado com patógenos específicos, transmitidos por fontes externas, pois não fazem parte da microbiota normal. Sugeriu que a única fonte provável seria o contato com outros membros infectados da família.

Falar de promoção e atenção primária em saúde bucal é falar em puericultura odontológica, neste contexto, a mãe torna-se responsável pela saúde bucal de seu filho. Sabe-se que grande parte das doenças que acometem a cavidade bucal são causadas por micro-organismos, que são transmitidos de um indivíduo para o outro. Portanto, para que uma criança tenha uma boa condição bucal, é necessário que toda a sua família apresente esta condição, principalmente a mãe, pois esta é a grande responsável pela formação da microbiota bucal de seus filhos. 


\section{Conclusão}

Concluiu-se com esta pesquisa que o padrão de transmissibilidade dos micro-organismos bucais é determinado pelas mães, ou seja, transmissão vertical, pois as mães que possuíam a doença cárie tinham filhos que também a apresentaram, já as mães que não apresentaram esta doença, os filhos também não apresentaram.

$\mathrm{Na}$ análise microscópica realizada para identificar os grupos bacterianos mais prevalentes na cavidade bucal, constatou-se que todas as amostras, em ambos os meios, demonstraram aspectos morfológicos de cocos e estreptococos, tanto nas mães quanto nos filhos. Em menor número foi detectado a presença de estafilococos, nos pares analisados. Quanto aos bacilos, identificou-se maior prevalência para as mães. Portanto, é necessário conhecer o padrão microbiano e sua transmissão entre os indivíduos, principalmente entre pares mãe/filho, visto que é de suma importância conscientizar os responsáveis, por meio de programas preventivos, para evitar que aconteça a transmissão e consequentemente, a redução do risco de contaminação e desenvolvimento da doença cárie nas crianças, melhorando a condição de saúde bucal da população.

\section{Referências}

ALALUUSUA, S.; ASIKAINEN, S.; LAL, C. H. Intranfamilial transmission of ActinobacillusActinomyce temcomitans. J Periodontol, v. 62, n. 3, p. 207-210, Mar. 1991.

BERKOWITZ, R. J.; JORDAN, H.V.; WHITE, G. The early establishment of Streptococcus mutans in the mouths of infants. Arch Oral Biol, v. 20, n. 171, 1975.

BONECKER, M. J. S.; GUEDES-PINTO, A. C., WALTER, L. R. F. Prevalência, distribuição e grau de afecção de cárie dentária em crianças de 0 a 36 meses de idade. Rev. Ass. Paul. Cirurg. Dent., v. 51, n. 6, p. 535-540, 1997.

BRASIL. Ministério da Saúde. Secretaria de Atenção à Saúde. Projeto SB Brasil. Condições de saúde bucal de população brasileira. Resultados principais. Brasília, DF: CoordenaçãoNacional de SaúdeBucal, 2004.

CARLSSON, J.; OLSSON, B.; BRATTHALL, D. The relationship between the bacterium Streptococcus mutans in the saliva and dental caries in children in Mozambique. Archs Oral Biol. 1985; 30: 265-268.

CAULFIELD, P. W. et al. Initial acquisition of mutans streptococci by infants: evidence for a discrete window of infectivity. J. Dent. Res., v. 72, n. 1, p. 37-45, 1993.

CORRÊA.; M. S. N. P., Odontopediatria na primeira infância. São Paulo: Santos; 1998.

DIAS, D. M .A. et al. Levantamento epidemiológico da cárie dental em crianças de 0 a 5 anos na região do Distrito Federal, no ano de 1993. Rev. de Saúde do Distrito Federal, v. 6, n. 1, p. 21-26, 1995.
DUTRA, G. V.; AZEVEDO, I. D.; FIGUEIREDO, M. C. Cárie dentária: uma doença transmissível. Revista Brasileira de Odontologia, 1997; 54(5): 293.

FERNANDES, F. R. C.; GUEDES-PINTO, A. C. Cárie Dentária. In: Guedes-Pinto, A.C. Odontopediatria, 6. ed. São Paulo: Santos, 1997. Cap. 21. p. 299-322.

FITZGERALD, R. J.; KEYES, P. H. Demonstration of etiologic role of streptococci in experimental caries in hamsters. J. Am. Dent. Assoc., v. 61, Jul., p. 9-19, 1960.

FUJIWARA, T.; et al. Caries prevalence and salivary mutans streptococci in 0-2 year-old children of Japan. CommunityDent. Oral Epidemiol., v. 19, n. 3, p. 151-154, 1991.

GUEDES-PINTO, A. C. Odontopediatria. 6. ed. São Paulo: Santos, 1997.

HUGOSON, A.; et al. Oral health of individuals aged 3-80 years in Jönköping, Sweden during 30 years (1973-2003). I. Review of findings on dental care habits and knowledge of oral health. Swed. Dent. J. v. 29, n. 4, p. 125-38, 2005.

IRFAN, U. M.; DAWSON, D. V.; BISSADA, N. F. Assessment of familial patterns of microbial infection in periodontitis, J Periodontol, v. 70, n. 11, p. 1406-1418, Nov. 1999.

JAHN, M. R.; JAHN, R. S. Fique atento: criança também tem gengivite. Rev. Assoc. Paul. Cir. Dent., v. 51, n. 4, p. 355-358, 1997.

KEYES, P. H. Recent advances in dental caries research. Bacteriol. Int. Dent. J., v. 12, p. 443-63, 1962.

NEWBRUN, E. Cariologia. São Paulo: Santos, 1988.

PIAZZINI, L. F. Periodontal screening and recording (PSR) application in children and adolescent. J. Clin. PediatrDent, v. 18, n. 3, p. 165-71, 1994.

PINTO, J.A.S. Transmissão de patógenos periodontais entre membros da família. Rer. Assoc. Paul. Cirurg. Dent., v. 52, n. 2, p. 163-164, mar./abr. 1998.

RAMOS, B. C.; MAIA, L. C. Cárie tipo mamadeira e a importância da promoção da saúde em crianças de 0 a 4 anos. Rev. Univ. São Paulo, v. 13, n. 3, p. 303-311, 1999.

ROCHA, A. M. L.; NASCIMENTO, R. M.; PEREIRA, V. A. S. Saúde oral em bebês. J. Bras. Odontopediatr. Odontol. Bebê, v. 7, n. 36, p. 204-210, 2004.

ROSELL, F. L.; MONTANDON-POMPEU, A. A. B.; VALSECKJ Jr., A. Registro periodontal simplificado em gestantes. Rev Saúde Pública. São Paulo, v. 33, n. 2, p. 1-11, abr. 1999.

SOCRANSKY, S. S.; MANGANIELLO, A. D. The oral 
microbiota ofmanfrombirthtosenility. J Peruidibtik, v. 42, n. 485,1971

TORRIANI, D. M. D.; BUSATO, A. L. S. Cárie Dental. In: BUSATO, A. L. S.; HERNANDEZ, P. A. G.; MACEDO R.

P. M. Dentística: Restaurações Estéticas. São Paulo: Artes Médicas, 2002. Cap. 1. p. 1-20.

WALTER, L. R. F.; et al. Cárie em crianças de 0 a 30 meses de idade e sua relação com hábitos alimentares. Enciel BrasOdontol, 1987; (1): 129-36.

ZAMBON, J. J. Microbiologia da doença periodontal. In: GENGO, R. J.; GOLDMAN, H. M.; COHEN, D. W. Periodontia Contenporânea. 3. ed. São Paulo: Editora Santos, 1999. Cap. 11, p. 147-160. 